\title{
Research on the ultraweak photon emission from anti-cancer plants
}

\author{
Ping $\mathrm{Wu}^{1}$, Xiang $\mathrm{He}^{1}$ \\ ${ }^{1}$ Dept. of Applied Physics, Nanjing University of Aeronautics and Astronautics, Nanjing, 210016, China. \\ Email:pwu2000@nuaa.edu.cn
}

Received 8 February 2009; revised 21 March 2009; accepted 23 March 2009.

\begin{abstract}
UPE (Ultraweak photon emission) is one kind of a common phenomenon in biological organisms. It contains a wealth of information of biological functions. In this paper, single photon counting system is used to measure UPE of some anticancer herbal plants. For the plants, the changes of UPE under different water condition are studied and the varying laws of ultraweak photon number with time are analysed. The results are higher fit double exponential decay law.
\end{abstract}

Keywords: Ultraweak Photon Emission; Photon Counting; Barbed Skullcap Herb; Pedate Pinallia Jackinthepulpit Rhizome; Cochinchnese Asparagus Root; Fitting

\section{INTRODUCTION}

In 1920's, A. G. Gurwitsch, a former Soviet Union's cell biologist, was the first to discover the phenomena of the ultraweak photon emission from biological object (UPE) during the period of the cell division of onion root tip [1]. UPE was able to be carried on the research until 1950's because of the restrictions of the experimental means. In 1951, B. L. Strehler, et al. [2] observed the photon emission from green plants induced by light, and this phenomenon is called "delayed luminescence.” In 1955, the L. Coli group used the high sensitivity photomultiplier, which just came out, to detect the photon emission from the wheat, legumes and corn at the germination process [3]. From 1960's to1970's, the former Soviet Union scientists have researched except on plant but also on animal tissue like frog's nerve and muscle, mouse's liver and so on. They discovered that UPE is different from ordinary bioluminescence, for example fluorescence and so on, but is correlative with biological metabolism.

So far, many experimental results show that the presence of UPE in biological organisms including plants, animals, etc. UPE is an intrinsic and spontaneous process of biological organisms and is different from bioluminescence phenomena observed, for example, in fireflies or luminescent bacteria. UPE is not dependent on any particular enzyme or protein. It is the reflection of the general information of the biological function and has inherence relations with the life processes such as cellular metabolism, cell division, growth, death, mutation and cell-to-cell transmission of information. So, the ultraweak photons can transmit the information of biological objects and it is playing an increasingly important role in the development of biological science.

About UPE mechanism now there is no conclusion. There are two major kinds of explain separately in chemistry and in physics. In chemistry, the main explanation is "the mechanism of metabolize emission", which thinks that the oxidation of the unsaturated fatty acid produce peroxide free radical. The peroxide in excited state can be form when peroxide free radical compound, and then UPE will be generated when the peroxide withdraw from excited state [4]. In physics, F. A. Popp, et al. put forward "the mechanism of coherent emission” $[5,6]$. They think that UPE partly or wholly originate from the highly coherent electromagnetic field in biological system and the field is possibly the basis of communication between living tissues. The F. A. Popp's research on the organisms of the light-induced delayed luminescence indicate that the luminescence accord with the law of hyperbolic attenuation. This is precisely the important characteristic of coherent field [7]. But "the mechanism of metabolize emission" and "the mechanism of coherent emission” only can partially explain some experimental results for UPE. This reflects the complexity of UPE mechanism, as well as the limitation which the people knew to it.

At present, the research on UPE also exist a lot of important questions to be resolved, such as the mechanism of producing UPE, the detection technology of ultraweak photon and the interpretation information of UPE and so on. In this paper, we detect the UPE from some kind of anti-cancer plants by using photon count- 
ing system, and analyze the time varying law of biological photon counting.

\section{EXPERIMENT SYSTEM AND MATERIAL}

\subsection{Experiment System}

The output current signal of the photomultiplier tube is characteristic of the natural discretization under the weak light illumination. The single photon counting system makes use of the characteristic and adopt the technique of pulse height screening and digital counting, so it has high sensitivity. It can detect the very weak photon information whose intensity of the optical flow lower than the thermal noise level (10-14W) of photomultiplier under room temperature, and it can be used for the measure of UPE. The structure of the experiment system is shown in Figure 1. In measurement, the sampling interval is 3 minutes, the integral time is 1 minute.

\subsection{Experimental Material}

The leaves of anti-cancer plant including Barbed Skullcap Herb, Pedate Pinallia Jackinthepulpit Rhizome and Cochinchnese Asparagus Root are chosen as the measured samples. The UPE of the samples at different growth status have be measured by the single photon counting system and the correlation curves of the biological photon counting with time are described.

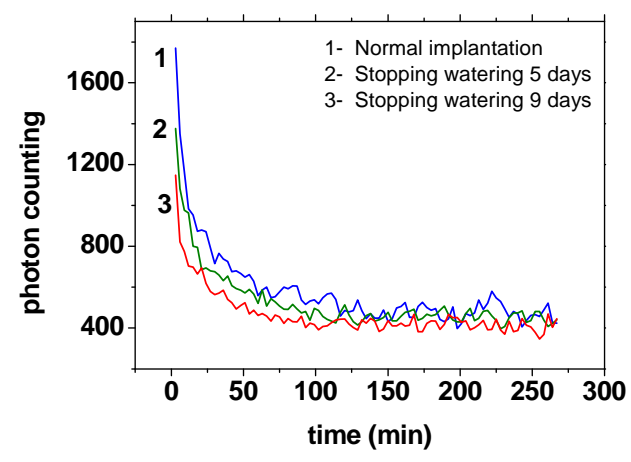

(a) Measuring curves of UPE

\section{MEASUREMENT RESULTS AND DIS- CUSSION}

\subsection{Measurement Results for Different Situations}

The UPE of the leaves for three plants in the normal implantation situation and the situation of stopping watering a few days are measured separately and the differences of UPE under different conditions are evident. The measuring curves and fitting curves for the photon counting of the samples with time are shown in Figure 2-Figure 4.

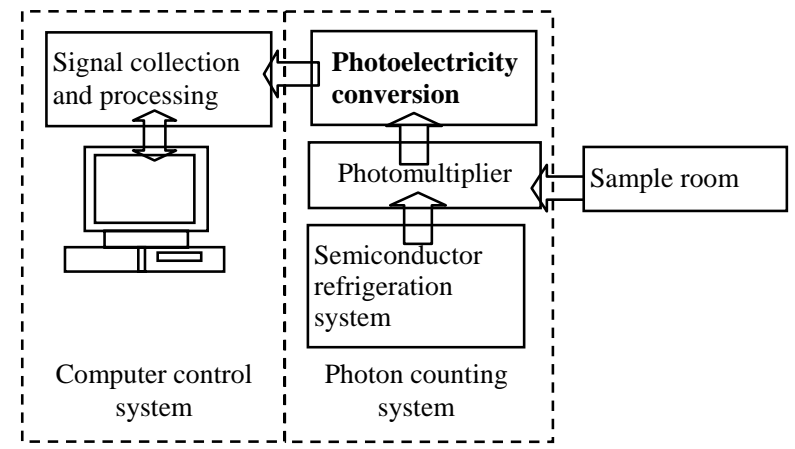

Figure 1. Structure of experiment system.

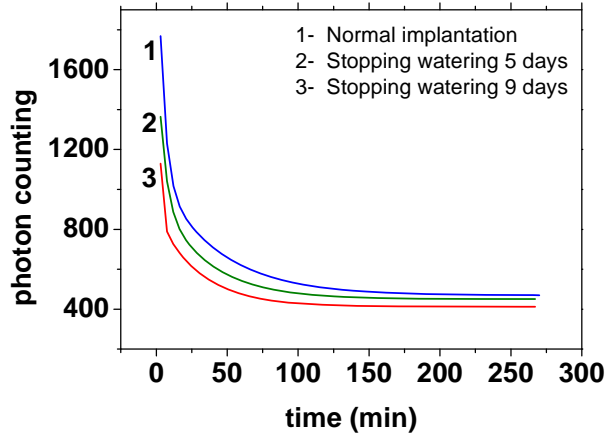

(b) Fitting curves with double exponential decay

Figure 2. Measuring curves and fitting curves of Barbed Skullcap Herb.

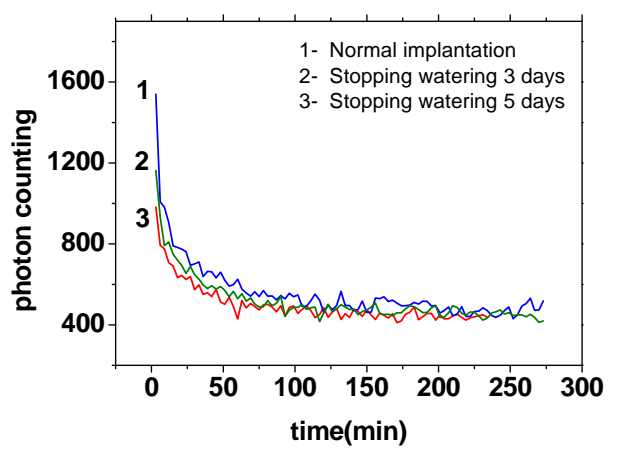

(a) Measuring curves of UPE

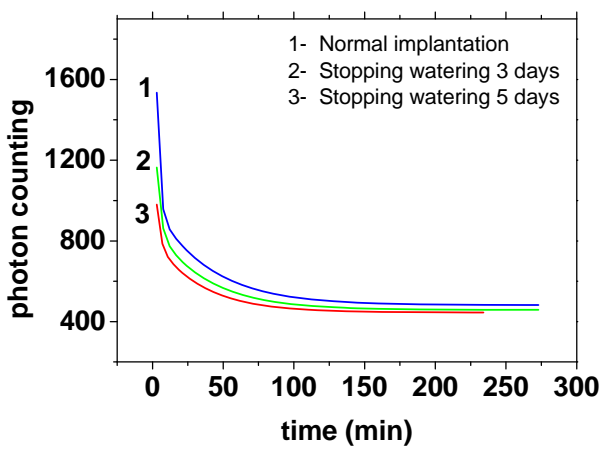

(b) Fitting curves with double exponential decay

Figure 3. Measuring curves and fitting curves of Pedate Pinallia Jackinthepulpit Rhizome. 


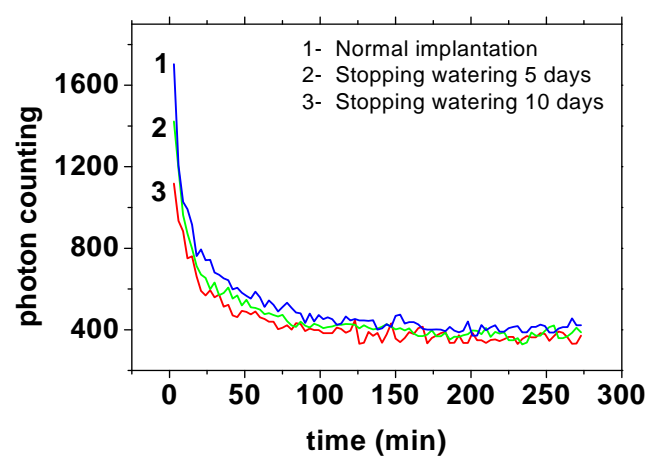

(a) Measuring curves of UPE

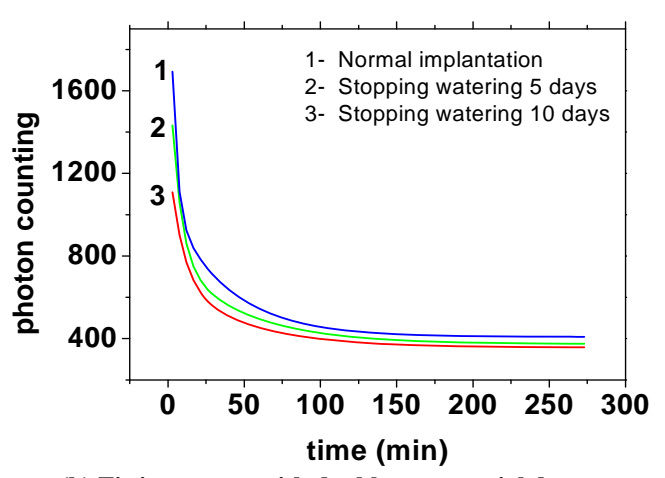

(b) Fitting curves with double exponential decay

Figure 4. Measuring curves and fitting curves of Cochinchnese Asparagus Root.

Table 1. Fitting results of Barbed Skullcap Herb.

\begin{tabular}{lccc}
\hline & $\begin{array}{c}\text { Double expo- } \\
\text { nential decay }\end{array}$ & $\begin{array}{c}\text { Exponential } \\
\text { decay }\end{array}$ & $\begin{array}{c}\text { Gaussian } \\
\text { function }\end{array}$ \\
\hline $\begin{array}{l}\text { Normal } \\
\text { implantation }\end{array}$ & 0.97083 & 0.9187 & 0.90616 \\
Stopping watering 5 days & 0.96989 & 0.94243 & 0.93253 \\
Stopping watering 9 days & 0.95414 & 0.91233 & 0.90341 \\
\hline
\end{tabular}

Table 2. Fitting results of Pedate Pinallia Jackinthepulpit Rhizome.

\begin{tabular}{llll}
\hline & $\begin{array}{l}\text { Double expo- } \\
\text { nential decay }\end{array}$ & $\begin{array}{l}\text { Exponential } \\
\text { decay }\end{array}$ & $\begin{array}{l}\text { Gaussian } \\
\text { function }\end{array}$ \\
\hline Normal implantation & 0.96815 & 0.88676 & 0.87291 \\
Stopping watering 3 days & 0.96843 & 0.92953 & 0.93457 \\
Stopping watering 5 days & 0.95613 & 0.93143 & 0.91942 \\
\hline
\end{tabular}

Table 3. Fitting results of Cochinchnese Asparagus Root.

\begin{tabular}{lccc}
\hline & $\begin{array}{l}\text { Double expo- } \\
\text { nential decay }\end{array}$ & $\begin{array}{l}\text { Exponential } \\
\text { decay }\end{array}$ & $\begin{array}{l}\text { Gaussian } \\
\text { function }\end{array}$ \\
\hline Normal implantation & 0.9875 & 0.94895 & 0.9394 \\
Stopping watering 5 days & 0.98748 & 0.94675 & 0.9352 \\
Stopping watering 10 days & 0.97057 & 0.93394 & 0.922 \\
\hline
\end{tabular}

From the measurement results, it is clear that the intensity of UPE from the samples display a marked decline under the lacking water condition, and the intensity will further reduce along with the increase in the number of lacking water days. This reflects the growth of plants for water-dependent, in the lacking water condition, the plants appeared the decline of the internal functions.

Comparing of the fitting curves under the lack of water in five days, it may be seen that the reduction of UPE from Barbed Skullcap Herb slower than Pedate Pinallia Jackinthepulpit Rhizome and Cochinchnese Asparagus Root. This is related to their own growth habit. Barbed Skullcap Herb has a certain water-retention capacity, and its branches or leaves, which have been picked off and exposed to the sun, can be survived after inserted into moist soil. Pedate Pinallia Jackinthepulpit Rhizome and Cochinchnese Asparagus Root are all delighted for moist, so the lack of water is of more influences on them.

\subsection{Emission Laws Discussion}

In order to study the law of UPE from the samples, the measured curves are respectively fitted with double exponential decay, exponential decay and Gaussian function. The results of three different fitting are shown in Tables 1-3.

It is not difficult to see from the results in Tables 1-3, the fitting of double exponential decay is the best of the three, and it is different from the coherent theory that thinks UPE accord with hyperbolic attenuation. So it reflects that UPE is a very complex biological system, not fully coherent mechanism but a variety of mechanisms have a role in it. There have been some research results shown that the dual-exponential decay law [8], but is still very difficult to explain theoretically. One view is that this is because there are a number of the coherent system in biology and there are interaction between them. In order to reveal the nature of UPE, it is required that a large amount of experimental and theoretical work to be done.

\section{REFERENCES}

[1] A. G. Gurwitsch, (1923) Arch Entw Mech Org, 100 (1), 11-40.

[2] B. L. Strehler and W. Arnold, (1951) J Gen Physiol, 34, 809-820.

[3] L. Colli, U. Facchini, and G. Guidotti, (1955) Further measurements on the bioluminescence of the seedlings, Experientia, 11, 479-481.

[4] X. Gang, (1994) The ultrawesk photon emission in plant and its application in agriculture, Physics, 9, 548-552.

[5] F. A. Popp, K. H. Li, W. P. Mei, et al., (1988) Physical aspects of biophotons. Experientia, 44, 576-585.

[6] F. A. Popp, (1988) Biophoton emission, Experientia, 44, 543-544.

[7] F. A. Popp, Q. Gu, and K. H. Li, (1994) Biophoton emission:Experimental background and theoretical approaches, Modern Physics Letters B, 8 (21\&22), 1272-1274.

[8] J. L. Chen and Z. G. Lu, (1999) Garlic Delaved Luminescence, Journal of Optoelectronics and Laser, 10, 365-367. 